\title{
La salud bajo la perspectiva estatal durante el varguismo
}

\section{Health from a State perspective under Vargas}

\author{
Karina Inés Ramacciotti \\ Profesora de la Universidad de Buenos Aires \\ rama@vianw.com.ar
}

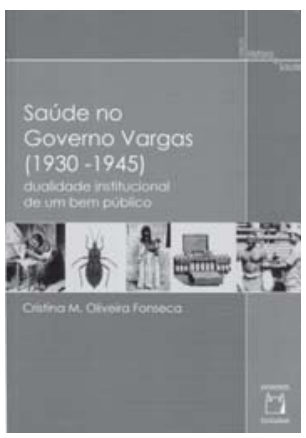

Fonseca, Cristina M. Oliveira. Saúde no governo Vargas (19301945): dualidade institucional de um bem público. Rio de Janeiro: Ed. Fiocruz, 2007. 298p. (Coleção História e Saúde). $\longrightarrow$ ristina Oliveira Fonseca nos ofrece en Saúde no governo Vargas (1930-1945) un aporte sustancial para las investigaciones que tengan como objetivo desentrañar la compleja construcción de las políticas sociales y su armado institucional. Además, enriquece la producción historiográfica latinoamericana ya que sus ideas permiten ir trazando comparaciones entre los diversos procesos de constitución de políticas sanitarias en el Cono Sur. A partir del estudio pormenorizado de las políticas de salud y la indagación del armazón administrativo, se podrá ir conformando un interesante corpus para desentrañar las particularidades de dichas realidades y bucear en las contraposiciones o en los diálogos planteados entre las políticas surgidas en otras latitudes.

El libro está constituido por cuatro capítulos. El primero de ellos plantea las principales vertientes de análisis teórico por los cuales se abordó el estudio de la política social en Brasil. Fonseca plantea que su opción estará centrada en los aportes del llamado neoinstitucio-

nalismo y, en función de ello, en el estudio del entrecruzamiento entre las ideas, los actores, las reglas constitucionales, los resultados electorales y las instituciones conformadas. Se corre de las miradas que le dan primacía a las elecciones racionales y al análisis esquemático entre medios y fines y, por el contrario, presta atención a las disputas políticas entre los procesos de creación de áreas de servicio, de construcción de grupos profesionales y del marco político partidario en el que se desarrollan las ideas y las normativas.

La autora, si bien no niega la ruptura que significó el varguismo para la historia brasilera, intenta repensar las continuidades y las novedades que se introdujeron en el período previo. Sostiene que estas ideas y las lógicas políticas partidarias influyeron en el proceso de constitución de las políticas de salud pública. Al mismo tiempo, al centrarse en el estudio de las políticas sanitarias, se aleja de los estudios que analizaron las políticas laborales y las estrategias de inclusión sanitaria que éstas generaron para la protección social de los trabajadores. La hipótesis que se plantea es que la política de salud pública implementada durante el período de Vargas constituyó un instrumento estatal que intentó incluir a los grupos sociales que las políticas laborales no abarcaban.

Si bien dialoga con los aportes que se centraron en el análisis de las políticas laborales, se diferencia de éstos ya que sostiene que éstas fueron producto de la presión de grupos 
sociales corporativos. En cambio, las políticas sanitarias fueron otorgadas por el Estado como respuesta a iniciativas del poder ejecutivo. La autora considera que la población civil no estaba presente como actor político y por lo tanto no interfirió sobre el diseño institucional. Quienes sí ocuparon un papel destacado en este proceso fueron los médicos sanitaristas. Sus ideas y propuestas fueron las que nutrieron la agenda estatal. No obstante, para lograr tal cometido fue necesario enfrentar disputas políticas partidarias que implicaron la intervención del Estado nacional en los ámbitos locales. Es decir, la centralización de la salud pública que, en el ideario de la época conduciría a la universalización de la ciudadanía social, chocó contra los poderes instituidos que alertaban sobre el peligro de perder la soberanía de sus instituciones. Las políticas de salud pública no implicaron una ruptura con la etapa previa sino más bien una incorporación de sus actores en tanto sus conocimientos técnicos y sus habilidades en la gestión de la salud pública. La bandera del saneamiento - enarbolada por los médicos sanitaristas - fue incorporada y fue funcional al proyecto nacionalista autoritario del varguismo.

El segundo capítulo se centra en las interpretaciones de los actores políticos que tuvieron papel destacado en la constitución de la salud pública durante el gobierno de Vargas. El recorte elegido está basado en aquellos intelectuales que integraron equipos de gobierno y que indirectamente tendrán un papel relevante en la efectivización de un programa político que buscará la conexión entre las ideas y su aplicación administrativa. En función de esto se centra en dos personajes claves: Oliveira Vianna y Azevedo Amaral. Ambos, si bien presentaban ciertas diferencias en cuanto a la raíz de los problemas sociales brasileños, coincidían en su notoria oposición al sistema liberal y sus propuestas de implantación de un Estado fuerte y centralizado como vía privilegiada para neutralizar los poderes locales constituidos y dar respuesta a las cuestiones sociales problematizadas. A tono con lo que sucedía en la mayoría de los países de Occidente en los años 1930, el Estado empieza a ser visualizado como el único organismo capaz de establecer un orden racional y conferirle una dirección institucional acorde.

La autora rastrea los debates en torno a la salud pública a través de los artículos publicados en el principal órgano de difusión y propaganda del varguismo: la revista Cultura Política. En estos escritos se vislumbran ciertas preocupaciones comunes y las soluciones propuestas para el futuro del país. Es por tal motivo que esta publicación se convierte en un escenario privilegiado para revisar las ideas que orientarán tanto la enunciación como la conformación del engranaje institucional.

El capítulo tercero rastrea como las tendencias ideológicas se plasmaron en el ámbito político a partir de los debates parlamentarios. En forma paralela analiza los primeros años de funcionamiento del Ministerio de Educación y Salud Pública (Mesp). En sus inicios el Mesp estuvo signado por la rotación de sus ministros. Es recién en 1934, cuando asumió Gustavo Capanema, que se consolidó un período de mayor estabilidad que duraría hasta el final del varguismo. Esta inicial alteración institucional es vista como parte de una indefinición en las reglas del juego y fruto de una inestabilidad política. La creación del Ministerio estuvo permeada por la diversidad partidaria y enfrentó las tensiones entre encarar una política nacional o mantener las autonomías estaduales. La solución a este 
debate vino de la mano de un gobierno autoritario que logró la centralización administrativa y, no por eso, eliminó la autonomía de los servicios locales.

El capítulo cuarto investiga los vínculos existentes entre los cambios realizados en salud pública y las influencias internacionales por medio de las relaciones establecidas en las conferencias sanitarias. Estos espacios, que combinan lineamientos procedentes de Estados Unidos y discusiones de las propias realidades nacionales, fueron brindando recomendaciones que fueron tomadas para la delimitación de los diseños normativos y administrativos. La afinidad entre la agenda internacional y el proyecto de construcción nacional, planteado durante el gobierno de Vargas, debe ser considerado como un importante factor de fortalecimiento interno de los propósitos gubernamentales, asimismo ausculta en las reformas realizadas en los sistemas distritales y en los procesos que buscaron la profesionalización y la especialización técnica. Es en este dispositivo político en el cual los médicos sanitaristas tomaron un rol protagónico y se constituyeron en un actor clave en el proceso de construcción de la salud pública, partiendo de su injerencia en el afianzamiento de las áreas de intervención social del Estado y, en forma paralela, en el intento de lograr la universalización en los servicios sanitarios. Así pues las preocupaciones de los médicos sanitaristas compuestas, entre otras cuestiones, por realizar un metódico relevamiento bioestadístico, instalar centros de salud, realizar campañas sanitarias, conformar espacios formativos para los médicos sanitaristas, las enfermeras y los técnicos, la intención de crear hospitales - que fueran al mismo tiempo centros asistenciales y preventivos - pasaron a ser parte de la agenda estatal. No obstante, Fonseca demuestra que este proceso no fue lineal y estuvo cargado de complejidades en las que las alianzas políticas tuvieron un papel destacado.

Claro está que el foco del libro está centrado en la mirada estatal y en las voces que tuvieron un papel preponderante en el armado de las políticas públicas. En efecto, los intentos de socialización y de universalización de la salud pública tienen un marcado protagonismo. De esta forma, esta investigación evitó restringirse a aquellos aspectos de control social con los que frecuentemente se asocian a la política sanitaria. Sin embargo, a partir de este libro se abre una agenda para futuras investigaciones que podrán escudriñar las distancias entre estos postulados normativos y las prácticas efectivamente alcanzadas, las limitaciones y exclusiones que se produjeron en el propio proceso de implementación de estas medidas, las críticas que otros actores pudieron haber postulado durante la puesta en práctica de estas normativas y los alcances o limitaciones presupuestarios para llevar a cabo tal propuesta centralizadora.

En suma, la estructura del libro es clara, ordenada y posee un detallado desglose de fuentes. Además, permite al lector seguir el derrotero de la reflexión y el sentido de la argumentación de un tema tan complejo como es el estudio de las políticas sanitarias y su andamiaje administrativo. 